\title{
Effect of delay in layering on the incremental adhesion of indirect dental composite resins
}

\author{
Özcan, Mutlu ; Pekkan, Gurel
}

\begin{abstract}
Adhesion of the new layer of indirect composite resin (ICR) to the already polymerized one may be affected when the time between the applications of subsequent layers is prolonged. The aim of this study was to compare the shear bond strength and degree of conversion (DC) of two ICR systems with different compositions and adhesive promoters, relayered after four time points. Disk shaped ICR materials (ICR1=Sinfony and ICR2=Targis) ( $\mathrm{N}=96, \mathrm{n}=48$ per material) were fabricated and processed according to each manufacturer's instructions. They were then randomly assigned to 4 groups. While immediate layering acted as the control group, after $5 \mathrm{~min}, 24 \mathrm{~h}$ and 1-week delay, a new layer of the ICR of the same kind with the substrate was adhered to the substrate in polyethylene molds. The bonded specimens were loaded under shear $(1 \mathrm{~mm} / \mathrm{min})$ and bond strength was calculated. DC of ICR1 and ICR2 were similar (75 $\pm 1,75 \pm 2$, respectively). Delay in relayering at different timepoints did not significantly affect the adhesion between the incremental layers of ICR1 (32-34 MPa) compared to the control group (34 MPa), but the adhesion between the layers of ICR2 showed decreased bond strength after $24 \mathrm{~h}(30.9)$ and especially more after 1 week (25 MPa) compared to immediate layering (38.9 MPa). The effects of ageing before bonding additional layers of ICRs is variable, and depends on the chemical formulation of the ICR as reflected in the different brands.
\end{abstract}

DOI: https://doi.org/10.1016/j.ijadhadh.2012.06.008

Posted at the Zurich Open Repository and Archive, University of Zurich ZORA URL: https://doi.org/10.5167/uzh-75629

Journal Article

Accepted Version

Originally published at:

Özcan, Mutlu; Pekkan, Gurel (2012). Effect of delay in layering on the incremental adhesion of indirect dental composite resins. International Journal of Adhesion and Adhesives, 39:15-20.

DOI: https://doi.org/10.1016/j.ijadhadh.2012.06.008 
Effect of delay in layering on the incremental adhesion of indirect dental composite resins

\section{Mutlu Özcan ${ }^{a}, *$, Gurel Pekkan ${ }^{b}$}

${ }^{a}$ University of Zürich, Dental Materials Unit, Center for Dental and Oral Medicine, Clinic for Fixed and Removable Prosthodontics and Dental Materials Science, Zürich, Switzerland

${ }^{b}$ Dumlupinar University, Faculty of Dentistry, Tavsanli Yolu 10. Km., 43270 Kutahya, Turkey

Short Title: Effect of delayed layering on the composite-composite adhesion

*Correspondance to: Prof. Dr. med. dent. Mutlu Özcan, University of Zürich, Dental Materials Unit, Center for Dental and Oral Medicine Clinic for Fixed and Removable Prosthodontics and Dental Materials Science, Plattenstrasse 11, CH-8032, Zürich, Switzerland. Tel: +41-44-63 45600, Fax: +41-44-63 44305. e-mail: mutluozcan@hotmail.com (M. Özcan) 


\section{ABSTRACT}

Adhesion of the new layer of indirect composite resin (ICR) to the already polymerized one may be affected when the time between the applications of subsequent layers is prolonged. The aim of this study was to compare the shear bond strength and degree of conversion (DC) of two ICR systems with different compositions and adhesive promoters, relayered after four time points. Disc shaped ICR materials (ICR1=Sinfony and ICR2=Targis) $(\mathrm{N}=96, \mathrm{n}=48$ per material) were fabricated and processed according to each manufacturer's instructions. They were then randomly assigned to 4 groups. While immediate layering acted as the control group, after 5 minutes, 24 hours and 1-week delay, a new layer of the ICR of the same kind with the substrate was adhered to the substrate in polyethylene moulds. The bonded specimens were loaded under shear $(1 \mathrm{~mm} / \mathrm{min})$ and bond strength was calculated. DC of ICR1 and ICR2 were similar $(75 \pm 1,75 \pm 2$, respectively). Delay in relayering at different timepoints did not significantly affect the adhesion between the incremental layers of ICR1 (32-34 MPa) compared to the control group (34 $\mathrm{MPa})$, but the adhesion between the layers of ICR2 showed decreased bond strength after 24 hours (30.9) and especially more after 1 week (25 MPa) compared to immediate layering (38.9 MPa). The effects of ageing before bonding additional layers of ICRs is variable, and depends on the chemical formulation of the ICR as reflected in the different brands.

Keywords: Adhesion, Bond strength, Indirect composite resin, Layering 


\section{Introduction}

Dental composite resins are types of synthetic resins that are used in dentistry as restorative materials or adhesives [1]. Similar to other composite materials, a dental composite resin typically consists of a resinbased oligomer matrix usually based on bisphenol A-glycidyl methacrylate (bis-GMA) or urethane dimethacrylate (UDMA) consisting silanized inorganic fillers such as silicon dioxide (silica), barium, quartz or zirconia [2,3]. In today's dentistry, composite resins, applied directly by the clinician or fabricated indirectly in a dental laboratory and cemented in vivo, occupy a paramount position and present acceptable clinical performance with much lower costs than their ceramic counterparts $[4,5]$. Indirect composite resins (ICRs) were introduced in the dental market in an effort to address the disadvantages of the direct adhesive restorative materials such as technique sensitivity, difficult establishment of superior anatomical form, polymerization shrinkage or wear $[6,7]$. ICRs are polymerized outside the mouth, in polymerization units that are capable of delivering higher intensities and levels of energy for polymerization compared to those of hand-held polymerization units. Indirect fabrication of composite resin restorations in a laboratory or chairside on a plaster model, subsequently adhesively cemented, provide improved quality of interproximal tooth contact, that is the contact between restorative material and the adjacent tooth, compared to direct application of such restorations [4]. ICR materials provide alternative ways for clinicians to overcome some inherent deficiencies of direct composite resin restorations, including polymerization shrinkage, their inadequate polymerization in deep interproximal areas between two neighbouring teeth. Limited light transmission in such areas may yield to insufficient polymerization of the material [8-10].

Fixed dental prosthesis (FDP) is any dental prosthesis that is luted, screwed or mechanically attached or otherwise securely retained to natural teeth, tooth roots, and/or dental implant abutments that furnish the primary support for the dental prosthesis [11]. They can be metallic, ceramic or combination of both. ICRs are advantageous from optical point of view over metal-ceramic FDPs due the lack of metal in the reconstruction. Moreover, ICR FDPs show decreased wear of opposing dentition when compared to 
ceramic $[6,7]$. Also, finishing and polishing procedures are easy to perform and restorations can be repaired, if needed, using proper adhesive repair protocols $[8,9,12,13]$.

In order to overcome some of the deficiencies of the directly placed composite resins, attention has been directed to laboratory-processed composite resins. During the last two decades ICRs have gone through substantial changes in their process and compositions [7]. Ultra-small filler particles and polyfunctional methacrylate monomers are frequently used in ICRs [14,15]. Compared with direct composites, they are processed utilizing different laboratory techniques based on combinations of heat, pressure, vacuum and photo-polymerization. Indications of ICRs are inlays, onlays, veneers, single-unit and short-span anterior or posterior FDPs $[7,9,10,12,13]$.

A variety of materials with remarkable differences in composition, polymerization modes and conditions comprise the second generation of the laboratory-processed ICRs [16-23]. Second generation ICRs became available in 1995 and their inherent characteristics and clinical performance have not been widely investigated $[6,8,24,25]$. Although the recently introduced systems claim improved clinical performance and optical properties, some studies noted delamination of the veneering ICR from the substructure that is attributed to layering techniques used during the fabrication process $[5,26,27]$. The reason for this could be associated with the inadequate adhesion during incremental build-up between the highly converted ICR layers [28]. In general, adhesion between two composite resin layers is achieved in the presence of an oxygen-inhibited layer of unpolymerized resin [29-31]. Yet, controversial opinions exist on the effect of oxygen-inhibited layer on the adhesion between two composite resin layers [32-35]. Considering the time needed for the completion of an ICR restoration that often ranges from some minutes to hours, changes in the oxygen-inhibited layer could affect the adhesion between the layers during build-up [36,37]. In some cases, especially after clinical trial, colour adjustments may necessitate addition of new layers even after some days. Adhesion between two composite resin layers is achieved in the presence of an oxygeninhibited layer of unpolymerized resin but radical half-life decreases by time [29-31]. Thus, it can be hypothesized that adhesion between ICR layers can be impaired when relayering is performed at delayed 
time points compared to immediate incremental layering. While manufacturers of some ICR systems recommend the use of silane coupling agent between the increments to increase the wettability of the subsequent increment, others suggest the use of methacrylate based adhesive resin to achieve interpenetrating polymer network to activate the substrate surface for co-polymerization [28].

The objectives of this study therefore were to evaluate a) the degree of conversion and b) the incremental bond strength of ICR substrate and adherend in two systems with different compositions and adhesive promoters, relayered after four time points.

\section{Experimental}

\subsection{Materials and Methods}

The brands, main chemical compositions, corresponding polymerization modes, batch numbers, manufacturers, the shades of the ICRs and the conditioning materials used for the experiments are listed in Table 1.

Cylindrical cavities (diameter: $5 \mathrm{~mm}$, height: $3 \mathrm{~mm}$ ) prepared in auto-polymerized polymethylmethacrylate (Autoplast, Candulor AG, Wangen, Switzerland) surrounded by a PVC cylinder (3 specimens per cylinder) were filled with either flowable ( $n=48,12$ per group) (ICR1-Sinfony) or packable ICRs ( $\mathrm{n}=48,12$ per goup) (ICR2-Targis). The unpolymerized composite resins were packed into the cavities with a hand instrument and photo-polymerized incrementally in layers of not more than $2 \mathrm{~mm}$ (Figs. 1a-d). Each increment was photo-polymerized initially with a halogen polymerization unit (Demetron LC, SDS Kerr, Orange, CA, USA) for 40 seconds from a constant distance of $2 \mathrm{~mm}$ from the surface. Light intensity $\left(800 \mathrm{~mW} / \mathrm{cm}^{2}\right)$ was verified by a radiometer (Demetron LC, SDS Kerr) after fabrication of every 12 specimen. The surface layer was flattened by translucent Mylar strip (KerrHawe SA, Bioggio, Switzerland) in order to create a smooth surface. ICR1 and ICR2 specimens were further subjected to oven polymerization. For ICR1 specimens, preliminary polymerization was achieved with Visio Alpha Unit (3M ESPE AG, Seefeld, Germany) (400 mW/cm², Programme 3, no vacuum) for 5 minutes. A second cycle of 
polymerization was performed for 15 minutes in the Visio Beta Vario Unit (3M ESPE AG) $\left(40^{\circ} \mathrm{C}\right.$ with vacuum, $470 \mathrm{~mW} / \mathrm{cm}^{2}$ ). For ICR2 specimens, preliminary polymerization was performed with Targis Quick Unit (Ivoclar Vivadent AG, Schaan, Liechtenstein) for 5 minutes $\left(300 \mathrm{~mW} / \mathrm{cm}^{2}\right)$. A second cycle of polymerization was made for 25 minutes in the Targis Power Unit (Ivoclar Vivadent AG) $\left(68^{\circ} \mathrm{C}\right.$ with vacuum, $400 \mathrm{~mW} / \mathrm{cm}^{2}$ ) (Table 1).

The specimens of the control groups for both ICR1 and ICR2 were conditioned either with their corresponding adhesive (Sinfony Activator Resin, 3M ESPE AG) or wetting agent (Targis Wetting Agent, Ivoclar Vivadent AG), respectively using a microbrush and air-thinned. Sinfony Activator Resin was photopolymerized for 10 seconds. Immediately, a new layer of ICR of the same substrate material was adhered onto the conditioned substrates using translucent polyethylene moulds (inner diameter: $3.6 \mathrm{~mm}$, height: 5 $\mathrm{mm}$ ) and photo-polymerized for 40 seconds. This group acted as the control group.

Five minutes, 24 hours and 1 week after conditioning each ICR resins with their corresponding surface activator, a new layer of ICR of the same substrate material was adhered onto the conditioned substrates as described above. One operator (M.Ö.) carried out the bonding procedures throughout the experiments. The ICR was packed against the substrate incrementally with a hand instrument and photo-polymerized in two layers of not more than $2 \mathrm{~mm}$. Each layer was polymerized for 40 seconds. After polymerization, the polyethylene moulds were gently removed from the test specimens. The specimens were then stored in a dark box in dry conditions for 24 hours at $37^{\circ} \mathrm{C}$ until the testing procedures.

Specimens were mounted in the jig of the Universal Testing Machine (Zwick ROELL Z2.5 MA 18-1-3/7, Ulm, Germany) and shear force was applied to the adhesive interface until failure occurred. The load was applied to the adhesive interface, as close as possible to the surface of the substrate at a crosshead speed of $1 \mathrm{~mm} / \mathrm{min}$ and the results were analyzed with the software program (TestXpert ${ }^{\circledR}$, Zwick ROELL, Ulm, Germany). 


\subsection{Degree of conversion (DC)}

Additional disc shaped specimens (diameter: $5 \mathrm{~mm}$; thickness: $4 \mathrm{~mm})(\mathrm{N}=10, \mathrm{n}=5$ per ICR) were prepared for Sinfony and Targis. Each block was finished with wet silicone carbide papers up to 1200-grit and polished (Struers, Model DP 10, Panambra Ind. \& Tec. S.A., São Paulo, Brazil) with diamond paste (3 $\mu \mathrm{m})$.

The surfaces were analyzed by FT-Raman spectroscopy in order to evaluate the DC. FT-Raman Spectrometer (RFS 100/S, Bruker Inc, Karlsruhe, Germany) provided the spectra of the unpolymerized and polymerized resins after 100 scans. The spectrum resolution was $4 \mathrm{~cm}^{-1}$. The specimens were excited by the defocused line of an Nd:YAG laser source at $\lambda=1064.1 \mathrm{~nm}$ with maximum laser power of approximately $90 \mathrm{~mW}$ at the specimen. The unpolymerized resin was positioned on an aluminum rod in a sample holder mounted on an optical rail for spectrum collection. Three spectra of the top surface and another three spectra of the bottom surface were collected. Based on the measurements, one average spectrum for each surface was obtained. The average FT-Raman spectra were analyzed by selecting a range between 1590 and $1660 \mathrm{~cm}^{-1}$. The Raman peaks corresponding to the vibrational stretching modes at 1610 and $1640 \mathrm{~cm}^{-1}$ were fitted in Gaussian shapes to obtain the height of the peaks by software (Microcal Software Inc, Northampton, MA, USA). A comparison of the height ratio of the aliphatic carboncarbon double bond $(\mathrm{C}=\mathrm{C})$ at $1640 \mathrm{~cm}^{-1}$ with that of the aromatic component at $1610 \mathrm{~cm}^{-1}$ for the polymerized and unpolymerized conditions was performed in order to estimate the DC using the equation

(1). The aromatic $C=C$ peak at $1610 \mathrm{~cm}^{-1}$ originated from the aromatic bonds of the benzene rings in the monomer molecules, and its intensity remains unchanged during the polymerization reaction. The mean value and standard deviation of the $D C$ were calculated for each series where $R=$ the percentage of uncured resin that is determined by band height at $1640 \mathrm{~cm}^{-1} /$ band height at $1610 \mathrm{~cm}^{-1}$ :

$\begin{array}{ll}R_{\text {unpolymerized }}= & \text { band height at } 1640 \mathrm{~cm}^{-1} \\ & \text { band height at } 1610 \mathrm{~cm}^{-1} \\ R_{\text {polymerized }}= & \text { band height at } 1614 \mathrm{~cm}^{-1}\end{array}$


band height at $1640 \mathrm{~cm}^{-1}$

$D C$ of each ICR was then calculated using the following equation (2):

$D C=100^{*}\left[1-\left(R_{\text {polymerized }} / R_{\text {unpolymerized }}\right)\right]$

\subsection{Statistical analysis}

Statistical analysis was performed using SPSS 11.0 software for Windows (SPSS Inc., Chicago, IL, USA). Mean bond strength data (MPa) were submitted to analysis of variance (2-way ANOVA and Tukey's test) with the shear bond strength as the dependent, ICR material type [2 levels] and timepoints for layering [4 levels] as the independent factors. $P$ values less than 0.05 were considered to be statistically significant in all tests. DC data obtained from the top and bottom surfaces of the ICRs were analyzed by 2-way ANOVA. $P$ values less than 0.05 were considered to be statistically significant in all tests.

\section{Results}

Both the ICR material type $(P<.05)$ and layering time points $(P<.05)$ significantly affected the bond strength results (2-way ANOVA). Interaction terms were also significant $(P=.002)$ (Tukey's test).

While ICR1- ICR1 adhesion was not significantly changed when layering was performed at the tested timepoints (Immediate, 5 minutes, 25 hours, 1 week) $(34.5 \pm 5.3-32.2 \pm 4.4 \mathrm{MPa})(P=.939)$, ICR2-ICR2 adhesion showed significant decrease after 24 hours $(30.9 \pm 12.7 \mathrm{MPa})(P=.0028)$ and 1 week $(25 \pm 5.7$ $\mathrm{MPa})(P=.0025)$ delay of layering compared to immediate layering (control: $38.9 \pm 6.9 \mathrm{MPa})$. For ICR2, 5 minutes $(38.7 \pm 5.5 \mathrm{MPa})$ delay in layering did not show significant difference compared to the control group (Fig. 2).

DC of ICRs did not show significant differences between the experimental groups (top surface: $75 \pm 2$,

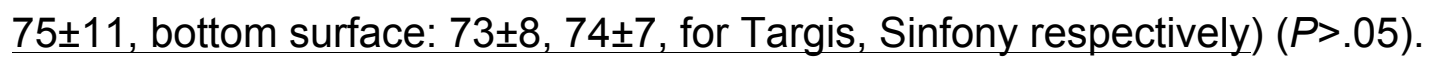




\section{Discussion}

The reported clinical failures of ICRs were related to chipping or pitting occasions ranging between $9-29 \%$ [4-6]. Since ICRs are fabricated based on layering principles, adhesion between the incremental layers is important in order to overcome such delamination or chipping problems clinically [38]. When working with ICR materials, the general principle is to minimize shrinkage during polymerizing a bulk of material. Therefore, incremental layering techniques should be implemented. Although controversial opinions exist $[39,40]$, it is generally accepted that with the incremental layering, shrinkage stress may be reduced since bulk volume and configuration factor decrease [41]. Incremental layering gives the clinician or the dental technician the chance to build-up the restoration on solid base as well as controlling the colour effect during layering [7]. However, this procedure may cost time and the working process may be delayed. Therefore, this study compared the effect of delayed layering with immediate layering simulating the time that is needed to complete a multiple-unit ICR FDP on the incremental adhesion of two types of ICRs. While ICR1 was not affected when layering was performed at the tested timepoints, the bond strength results decreased for the ICR2 with the increase in relayering time. Thus, since ICR1-ICR1 adhesion was not affected from delayed layering, the hypothesis that adhesion between ICR layers can be impaired when layering is performed at delayed timepoints compared to immediate incremental layering can only be partially accepted.

Although the polymerization methods for the two materials studied are not identical, the working principles of these methods are similar. The significant differences between the bond strengths of ICR1 and ICR2 may be referred to several other factors. One reason for this could be attributed to the slight variations between the polymerization devices. Currently available ICRs are often polymerized utilizing polymerization devices in which higher degree of conversion could be expected as a result of heat and light combination [42]. In this study, ICR1 was polymerized in such a device in total 20 minutes with the second polymerization cycle being at $40^{\circ} \mathrm{C}$. On the other hand, ICR2 was polymerized in total for 30 minutes at $68^{\circ} \mathrm{C}$. The additional heat and prolonged time of polymerization might have contributed to the 
better polymerization thereby, less adhesion with the subsequent adherend layer in the ICR2 material. However, the DC of both materials was statistically similar. Therefore, different polymerization regimes used to polymerize materials with varying constituents in this study make it difficult to reliably explain the differences in results. Further studies are needed to explain the time dependent bond strength decrease between aged and fresh ICRs with other surface characterization and modelling methods after aging them at different timepoints.

Polymerization characteristics of ICRs also vary depending on the power output of light source at polymerizing wavelength, type and geometry of light transmission system, and the type of composite resin. Laboratory processed composite resins use photo-polymerizing units that combine intense visible light (320 to $400 \mathrm{~nm}$ ) and heat that increase the conversion of monomer to polymer. Reduced degree of conversion may decrease the mechanical properties of composite resins $[29,43]$. The more intense the light source, the more photons available for absorption by photosensitizers $[15,26]$. Heat polymerizing in addition to visible-light polymerizing has been shown to substantially increase the degree of conversion [37] and reduce the oxygen inhibition of polymerization [31,37,44]. Adequate polymerization is a crucial factor in obtaining optimal physical properties and clinical performance of ICR restorative materials [6]. It is therefore desirable for a dental composite resin to convert most of its monomer to polymer during the polymerization reaction to achieve the best physical and biological properties $[29,43]$. However, this may then result in a more brittle material.

In this study, satisfactory bond strengths were obtained from both ICR systems tested at all time points, however, with some variations between ICR types. Bond strength is dependent on unconverted $\mathrm{C}=\mathrm{C}$ double bonds on the resin, which may be attributed to either to a low conversion rate or a high matrix portion [45]. The bond between the substrate and new resin is also based on unreacted $\mathrm{C}=\mathrm{C}$ double bonds of the functional groups on the surface of the polymer matrix [46]. A high degree of conversion that resulted from the use of heat and light used for polymerization causes improvement in mechanical strength and hardness but on the other hand makes the attachment of the new composite resin more difficult [17- 
21]. As stated earlier, adhesion between two composite resin layers is achieved in the presence of an oxygen-inhibited layer of unpolymerized resin [29-31]. Although, there are controversial studies [32-35], changes in the oxygen-inhibited layer may have significantly decreased the adhesion between the layers of ICR2 after one week. The thickness and quality of the oxygen-inhibited layer requires further research. Since similar conversion values were obtained for both ICRs, silane coupling agent and the wettability of the adhering resin seems to have more importance in the obtained results. Furthermore, the radical halflife, surface roughness, viscosity of the materials should also be taken into consideration. Further studies are needed to test the wettability, surface roughness, and viscosity as well as oxygen-inhibited surface layer of ICR materials.

The delay in working time of 5 minutes, 24 hour or 1 week did not affect the adhesion of the new layer to the processed substrate significantly in the ICR1 group. This indicated that ICR1 must have a surface more suitable for chemical bonding. One reason for the non-significant difference between the delayed versus immediately layered control group, may be related to the function of adhesive resin that may bond covalently to the pendent, unreacted methacrylate groups. Intermediate resin has been reported earlier to cause swelling of the composite substrate surface with different solvents and the use of low-viscosity adhesive resin influence the bond between two composite resins [46]. The functions of adhesive resin, prior to new resin application during layering, are to achieve better wetting of the substrate surface and dissolve and swell the polymer surface of the substrate to some degree. According to the manufacturer's information, the Sinfony activator monomer system contains more than $90 \%$ by weight of monomer (octahydro-4,7-methano-1H-indenediyl)bis(methylene)diacylate), which is also the same monomer used in the chemical composition of ICR1. This molecule contains two diacrylate functional groups and an indenediyl group. The existence of indenediyl group increases rigidity of the molecule that might have influenced both the dissolving capability of Sinfony activator monomer system on the substrate surface. Advantages of this monomer are its low polymerization shrinkage and its hydrophobic middle part that is 
indedendiyl. It can be also assumed that the viscosity properties were close to that of the unfilled activator monomer that resulted in high bond strength.

The hydrophilic adhesive joint in ICR2 seemed to be weaker than that of ICR1. The wetting agent used in ICR2 system was a 3-methacryloxypropyltrimethoxy silane coupling agent. Silane treatment improves the wettability of the surface, affects the surface energy, hence its dispersion in the matrix. However, when little unconverted $\mathrm{C}=\mathrm{C}$ double bonds are available, these functions of silane could obviously not be profited in ICR2 group.

It was supposed that a certain percentage of unconverted $\mathrm{C}=\mathrm{C}$ double bonds are available even after laboratory processing [44]. The differences in the results between the two systems could be then also due to differences in polymerization and monomer formulation. In high molecular weight monomers such as bis-GMA or UDMA there is always an incomplete and significant concentration of unreacted $\mathrm{C}=\mathrm{C}$ remaining within the resin when it is polymerized with visible light and under heat $[47,48]$. In addition to the unreacted monomer, further unreacted $\mathrm{C}=\mathrm{C}$ structures may be present from the diluents such as TEGDMA or similar substances [47]. The insignificant but higher bond strength results, except for 1 week, obtained from ICR2 group could be based on UDMA matrix monomers existing in this ICR type. In FTIR (Fourier transformation infrared spectroscopic) evaluations, it was found that the UDMA/TEGDMA phase had a conversion rate of $70 \%$ and exhibited superior wear resistance, while the bis-GMA/TEGDMA had a conversion rate of $55 \%$ [49]. In ICRs with such matrix content, the possibility to obtain free radical polymerization bonding during layering is low because of relatively small number of unreacted $\mathrm{C}=\mathrm{C}$ double bonds on the polymer surface $[29,49]$.

It has been also previously shown that there is slow continuous increase in conversion of conventional photo-polymerized composite resins after initial photo activation [15,43]. Loza-Herrero et al. [15] reported that the delay more than 6 hours changed the conversion rate from $58 \%$ to $68 \%$. In the current study, the decrease in Targis group after 1-week delay in layering could also be due to continuation of conversion over 24 hours or one week. 
It would be favourable to maintain a chemically active composite resin surface to secure the chemical bond, but the light polymerization devices may overrule this advantage. The ICR products may profit from the use of an intermediate adhesive resin between layers after each polymerization cycle than the use of a silane coupling agent alone.

\section{Conclusions}

From this in-vitro study, the following conclusions were drawn:

1. Degree of conversion of the two ICRs tested was similar.

2. The effects of ageing before bonding additional layers of ICRs varied depending on the chemical formulation and polymerization method of the ICR as reflected in the different brands.

3. Delay in relayering did not affect the incremental adhesion between the layers of ICR1 (Sinfony) but ICR2 (Targis) showed decreased bond strength after 24 hours and more dramatically after 1 week.

4. Restorations made of ICR1 (Sinfony) can be relayered at delayed time points up to 1 week but ICR2 (Targis) should be processed preferably in one day in order not to experience decreased adhesion between the incremental layers which may clinically induce chipping problem.

\section{Acknowledgement}

The authors thank assistance of Dr. Darwesh Ahmed during bond test of this study. 


\section{References}

[1] W.J. O'Brien, Dental materials and their selection, 3rd ed., Chicago: Quintessence Pub. Co., (2002) $113-160$.

[2] A. Hervás-García, M.A. Martínez-Lozano, J. Cabanes-Vila, A. Barjau-Escribano, P. Fos-Galve, Composite resins. A review of the materials and clinical indications, Med. Oral Patol. Oral Cir. Bucal. 11 (2006) E215 - 220.

[3] B. Zimmerli, M. Strub, F. Jeger, O. Stadler, A. Lussi, Composite materials: composition, properties and clinical applications. A literature review, Schweiz Monatsschr. Zahnmed. 120 (2010) 972 - 986.

[4] C. Monaco, P. Baldissara, G.D. dall'Orologio, R. Scotti, Short-term clinical evaluation of inlay and onlay restorations made with a ceromer, Int. J. Prosthodont. 14 (2002) 81 - 86.

[5] D. Kukrer, D. Gemalmaz, E.O. Kuybulu, F.O. Bozkurt, A prospective clinical study of ceromer inlays: Results up to 53 months, Int. J. Prosthodont. 17 (2004) 17 - 23.

[6] J.S. Mendonça, R.G. Neto, S.L. Santiago, L.R. Lauris, M.F. Navarro, R.M. de Carvalho, Direct resin composite restorations versus indirect composite inlays: one-year results, J. Contemp. Dent. Pract. 11 (2010) $025-32$.

[7] B.E. Göncü, E. Ayna, P.K. Vallittu, L.V. Lassila, Load-bearing capacity of handmade and computeraided design--computer-aided manufacturing-fabricated three-unit fixed dental prostheses of particulate filler composite, Acta Odontol. Scand. 69 (2011) $144-50$.

[8] A.V. Pensler, R.L. Bertolotti, D. Miller, Building laminate veneers and fixed bridges with polymer glass technology, Compend. Contin. Educ. Dent. 18 (1998) 712 - 716, 718, 720.

[9] A. Woods, Artglass: A new restorative option to porcelain, Miss. Dent. Assoc. J. 54 (1998) 36.

[10] A. Kakaboura, C. Rahiotis, S. Zinelis, Y.A. Al-Dhamadi, N. Silikas, D.C. Watts, In vitro characterization of two laboratory-processed resin composites, Dent. Mater. 19 (2003) $393-398$.

[11] The glossary of prosthodontic terms. J. Prosthet. Dent. 94 (2005) $10-92$. 
[12] H.B. Dumbrigue, Composite indirect-direct method for fabricating multiple-unit provisional restorations, J. Prosthet. Dent. 89 (2000) $86-88$.

[13] T. Stober, H. Gilde, P. Lenz, Color stability of highly filled composite resin materials for facings, Dent. Mater. 17 (2001) $87-94$.

[14] P.C. Chung, S. H., Wei, I. R., Reynolds, In vitro testing of elastomeric modules, Br. J. Orthod. 16 (1989) $265-269$.

[15] M. A. Loza-Herrero, F.A. Rueggeberg, W.F. Caughman, G.S. Schuster, C.A. Lefebvre, F.M. Gardner, Effect of heating delay on conversion and strength of a post-cured resin composite, J. Dent. Res. 77 (1998) $426-431$.

[16] W. Saunders, Effect of fatigue upon the interfacial bond strength of repaired composite resins, J. Dent. $18(1990) 158-162$.

[17] M.R. Bouschlicher, J.W. Reinhardt, M.A. Vargas, Surface treatment techniques for resin composite repair, Am. J. Dent. 10 (1997) $279-283$.

[18] S. A. Shahdad, J. G. Kennedy, Bond strength of repaired anterior composite resins: an in vitro study, J. Dent. 26 (1998) $685-694$.

[19] N. Tanoue, H. Matsumura, M. Atsuta, Wear and surface roughness of current prosthetic composites after toothbrush/dentifrice abrasion, J. Prosthet. Dent. 84 (2000) 93 - 97.

[20] M.F. Almuammar, A. Schulman, F.S. Salama, Shear bond strength of six restorative materials, J. Clin. Pediatric. Dent. 25 (2001) $221-225$.

[21] C. Lucena-Martín, S. González-López, N.R.M. de Mondelo José, The effect of various surface treatments and bonding agents on the repaired strength of heat-treated composites, J. Prosthet. Dent. 86 (2001) $481-488$.

[22] T.M. Lastumaki, T.T. Kallio, P.K. Vallittu, The bond strength of light-curing composite resin to finally polymerized and aged glass fiber-reinforced composite substrate, Dent. Mater. 23 (2002) 4533 - 4539. 
[23] J.Y. Kim, P. Pfeiffer, W. Niedermeier, Effect of laboratory procedures and thermocycling on the shear bond strength of resin-metal bonding systems, J. Prosthet. Dent. 90 (2003) $184-189$.

[24] E. Nilsson, S. Alaeddin, S. Karlsson, P. Milleding, A. Wennerberg, Factors affecting the shear bond strength of bonded composite inlays, Int. J. Prosthodont. 13 (2000) $52-58$.

[25] M.N. Mandikos, G.P. McGivney, E. Davis, P.J. Bush, J.M. Carter, A comparison of the wear resistance and hardness of indirect composite resins, J. Prosthet. Dent. 85 (2001) 386 - 395.

[26] J., Li, Effect of surface properties on bond strength between layers of newly cured dental composites, J. Oral. Rehabil. 24 (1997) $358-360$.

[27] D. Dietschi, Layering concept in anterior composite restorations, J. Adhes. Dent. 3 (2001) $71-80$.

[28] M. Özcan, P. Alander, P,K. Vallittu, M.C., Huysmans, W. Kalk, Effect of three surface conditioning methods to improve bond strength of particulate filler resin composites, J. Mater. Sci. Mater. Med. 16 (2005) $21-27$.

[29] J.L. Ferracane, V.A. Marker, Solvent degradation and reduced fracture toughness in aged composites, J. Dent. Res. 71 (1992) $13-19$.

[30] W.J. Finger, K.S. Lee, W. Podszun, Monomers with low oxygen inhibition as enamel/dentin adhesives, Dent. Mater. 12 (1996) $256-261$.

[31] L.V.J. Lassila, T. Nohrstrom, P.K. Vallittu, The influence of short-term water storage on the flexural properties of unidirectional glass fiber-reinforced composites, Biomaterials. 23 (2002) 2221 - 2229.

[32] F.A. Rueggeberg, D.H. Margeson, The effect of oxygen inhibition on an unfilled/filled composite system. J. Dent. Res. 69 (1990) $1652-1658$.

[33] D. Truffier-Boutry, E. Place, J. Devaux, G. Leloup, Interfacial layer characterization in dental composite. J. Oral Rehabil. 30 (2003) $74-77$.

[34] S. Dall'Oca, F. Papacchini, C. Goracci, A.H. Cury, B.I. Suh, F.R. Tay, A. Polimeni, M. Ferrari, Effect of oxygen inhibition on composite repair strength over time. J. Biomed. Mater. Res. B Appl. Biomater. 81 (2007) $493-498$. 
[35] E.S. Shawkat, A.C. Shortall, O. Addison, W.M. Palin, Oxygen inhibition and incremental layer bond strengths of resin composites. Dent. Mater. 25 (2009) $1338-1346$.

[36] P. Dionysopoulos, D.C. Watts, Dynamic mechanical properties of an inlay composite, J. Dent. 17 (1989) $140-144$.

[37] K.J.M. Söderholm, M.J. Roberts, Variables influencing the repair strength of dental composites, Scand. J. Dent. 99 (1991) $173-180$.

[38] C.F. Stappert, S. Chitmongkolsuk, N.R. Silva, W. Att, J.R. Strub, Effect of mouth-motion fatigue and thermal cycling on the marginal accuracy of partial coverage restorations made of various dental materials, Dent. Mater. 24 (2008) $1248-1257$.

[39] A. Versluis, W.H. Douglas, M. Cross, R.L. Sakaguchi, Does an incremental filling technique reduce polymerization shrinkage stresses? J. Dent. Res. 75 (1996) $871-878$.

[40] C.E. Campodonico, D. Tantbirojn, P.S. Olin, A. Versluis, Cuspal deflection and depth of cure in resinbased composite restorations filled by using bulk, incremental and transtooth-illumination techniques. J. Am. Dent. Assoc. 142 (2011) $1176-1182$.

[41] J. Park, J. Chang, J. Ferracane, I.B. Lee, How should composite be layered to reduce shrinkage stress: incremental or bulk filling? Dent. Mater. 24 (2008) 1501 - 1505.

[42] R.O. Souza, M. Özcan, S.M. Michida, R.M. de Melo, C.A. Pavanelli, M.A. Bottino, L.E. Soares, A.A. Martin. Conversion degree of indirect resin composites and effect of thermocycling on their physical properties. J. Prosthodont. 19 (2010) $218-225$.

[43] V.J. Miletic, A. Santini, Remaining unreacted methacrylate groups in resin-based composite with respect to sample preparation and storing conditions using micro-Raman spectroscopy, J. Biomed. Mater. Res. B Appl. Biomater. 87 (2008) 468 - 474.

[44] N. Tanoue, M. Atsuta, H. Matsumura, Properties of a new photo-activated composite polymerized with three different laboratory photo-curing units, J. Oral. Rehabil. 30 (2003) $832-836$. 
[45] E.M. Souza, C.E. Francischone, J.M. Powers, R.N. Rached, S. Vieira, Effect of different surface treatments on the repair bond strength of indirect composites, Am. J. Dent. 21 (2008) 93 - 96.

[46] F.S. El-Askary, A.S. Fawzy, H.M. Abd Elmohsen, Tensile bond strength of immediately repaired anterior microfine hybrid restorative composite using nontrimmed hourglass specimens, J. Adhes. Dent. 11 (2009) $41-47$.

[47] Y.H. Bagis, F.A. Rueggeberg, The effect of post-cure heating on residual, unreacted monomer in a commercial resin composite, Dent. Mater. 16 (2000) $244-247$.

[48] M.H. Tabatabaei, S. Arami, S. Zandi, S.H. Bassir, Evaluation of Bis-GMA/TEGDMA monomers leaching from a hybrid dental composite resin, Minerva Stomatol. 60 (2011) $159-165$.

[49] F.A. Rueggeberg, R.G. Craig, Correlation of parameters used to estimate monomer conversion in a light-cured composite, J. Dent. Res. 67 (1988) 932 - 937. 


\section{Captions to tables and figures:}

Tables:

Table 1 The brands, main chemical compositions, corresponding polymerization modes, batch numbers, manufacturers, the shades of the ICRs and the conditioning materials used for the experiments.

\section{Figures:}

Figs. 1a-d. Specimen preparation procedures: a) cylindrical cavities (diameter: $5 \mathrm{~mm}$, height: $3 \mathrm{~mm}$ ) were prepared in auto-polymerized poly(methylmethacrylate) surrounded by a PVC cylinder (3 specimens per cylinder), b-c) unpolymerized ICRs were packed into the cavities with hand instruments not exceeding 2 $\mathrm{mm}$ and photo-polymerized, d) a new layer of ICR of the same substrate material was adhered onto the conditioned substrates using translucent polyethylene moulds (inner diameter: $3.6 \mathrm{~mm}$, height: $5 \mathrm{~mm}$ ) and photo-polymerized.

Fig. 2. Mean bond strength and standard deviations of ICR-ICR combinations, where the substrate and the adherend were of the same material (Sinfony-Sinfony, Targis-Targis), after immediate (control), 5 minutes, 24 hours and 1-week delay in layering. 


\section{Tables:}

Table 1 The brands, main chemical compositions, corresponding polymerization modes, batch numbers, manufacturers, the shades of the ICRs and the conditioning materials used for the experiments.

\begin{tabular}{|c|c|c|c|c|c|}
\hline Brand & $\begin{array}{l}\text { Chemical } \\
\text { composition }\end{array}$ & Polymerization mode & $\begin{array}{l}\text { Batch } \\
\text { number }\end{array}$ & Manufacturer & Shade \\
\hline Sinfony & $\begin{array}{l}\text { HEMA and } 10-30 \text { wt\% } \\
\text { octahydro-4,7- } \\
\text { methano-1H- } \\
\text { indenediyl) } \\
\text { bis(methylene)diacryla } \\
\text { te, } \\
\text { strontium-aluminium } \\
\text { borosilicate } \\
\text { glass, silicon oxide, } \\
\text { silane and } \\
\text { photoinitiators } \\
\text { Weight }(\%) \text { organic } \\
\text { fillers: } 50 \%\end{array}$ & $\begin{array}{l}\text { First cycle: Polymerization } \\
\text { for } 5 \text { minutes in the Visio } \\
\text { Alpha unit }\left(400 \mathrm{~mW} / \mathrm{cm}^{2},\right. \\
\text { Programme } 3 \text {, no vacuum) } \\
\text { Second cycle: } \\
\text { Polymerization for } 15 \\
\text { minutes in the Visio Beta } \\
\text { Vario unit }\left(40^{\circ} \mathrm{C} \text { with }\right. \\
\left.\text { vacuum, } 470 \mathrm{~mW} / \mathrm{cm}^{2}\right)\end{array}$ & 203216 & $\begin{array}{l}\text { 3M ESPE AG, } \\
\text { Seefeld, } \\
\text { Germany }\end{array}$ & A2 \\
\hline Targis & $\begin{array}{l}\text { bis-GMA 20\%, DDDMA, } \\
\text { UDMA, TEGDMA } \\
\text { Silanized barium glass } \\
\text { fillers, photoinitiators, } \\
\text { inhibitors and } \\
\text { pigments } \\
\text { Weight }(\%) \text { organic } \\
\text { fillers: } 46.2 \%\end{array}$ & $\begin{array}{l}\text { First cycle: Polymerization } \\
\text { for } 5 \text { minutes in the Targis } \\
\text { Quick unit. }\left(300 \mathrm{~mW} / \mathrm{cm}^{2}\right) \\
\text { Second cycle: } \\
\text { Polymerization for } 25 \\
\text { minutes in the Targis } \\
\text { Power unit }\left(68^{\circ} \mathrm{C} \text { with }\right. \\
\left.\text { vacuum, } 400 \mathrm{~mW} / \mathrm{cm}^{2}\right)\end{array}$ & 15605 & $\begin{array}{l}\text { Ivoclar Vivadent } \\
\text { AG, } \\
\text { Schaan, } \\
\text { Liechtenstein }\end{array}$ & $\mathrm{A} 2$ \\
\hline $\begin{array}{l}\text { Targis } \\
\text { Wetting } \\
\text { Agent }\end{array}$ & $\begin{array}{l}\text { 3- } \\
\text { methacryloxypropyltri } \\
\text { methoxysilane }\end{array}$ & & 815137 & Ivoclar Vivadent & \\
\hline $\begin{array}{l}\text { Sinfony } \\
\text { Activator }\end{array}$ & $\begin{array}{l}>90 \text { wt\% (octahydro- } \\
4,7 \text {-methano-1H- } \\
\text { indenediyl)bis(methyle } \\
\text { ne)diacrylate }\end{array}$ & & 034 & $3 M$ ESPE AG & \\
\hline
\end{tabular}

bis-GMA = Bis-phenol-A-glycidylmethacrylate,

UDMA = Urethane dimethacrylate,

TEGMA = Triethyleneglycol methacrylate,

HEMA $\quad=$ 2-hydroxyethyl methacrylate.

DDDMA $\quad=1,10$-Decanediol dimethacrylate 


\section{Figures:}

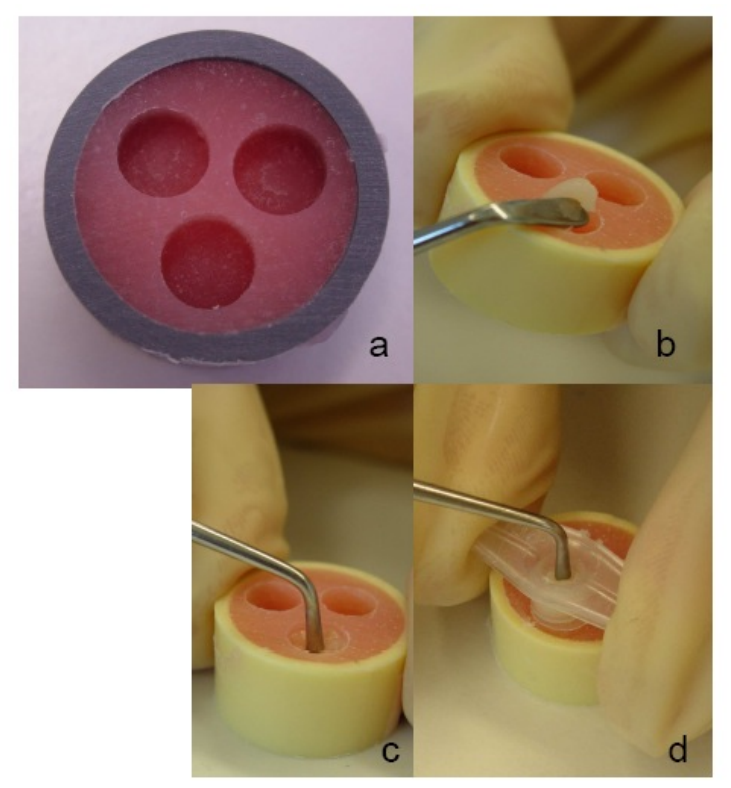

Figs. 1a-d. Specimen preparation procedures: a) cylindrical cavities (diameter: $5 \mathrm{~mm}$, height: $3 \mathrm{~mm}$ ) were prepared in auto-polymerized poly(methylmethacrylate) surrounded by a PVC cylinder ( 3 specimens per cylinder), b-c) unpolymerized ICRs were packed into the cavities with hand instruments not exceeding $2 \mathrm{~mm}$ and photopolymerized, d) a new layer of ICR of the same substrate material was adhered onto the conditioned substrates using translucent polyethylene moulds (inner diameter: $3.6 \mathrm{~mm}$, height: $5 \mathrm{~mm}$ ) and photo-polymerized.

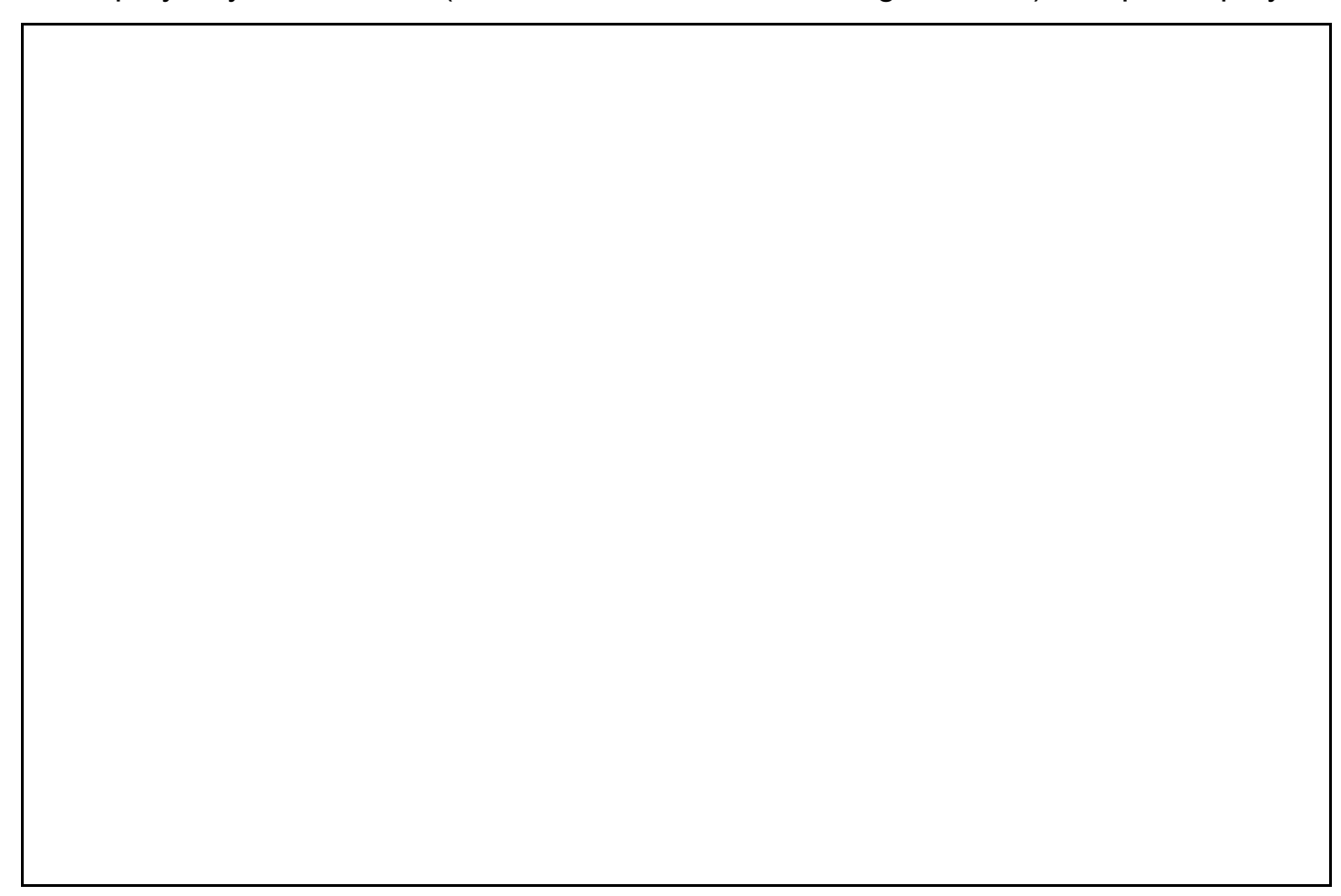

Fig. 2. Mean bond strength and standard deviations of ICR-ICR combinations, where the substrate and the adherend were of the same material (Sinfony-Sinfony, Targis-Targis), after immediate (control), 5 minutes, 24 hours and 1 -week delay in layering. 